\title{
Immune-enhancing screening of fourteen plants on murine macrophage RAW 264.7 cells
}

\author{
Sunggun Kim ${ }^{1}$, Eun-sang Jo ${ }^{1}$, Na-Yeun Kim", Kwang Woo Hwang ${ }^{2}$, So-Young \\ Park ${ }^{1 \star}$ \\ ${ }^{1}$ Laboratory of Pharmacognosy, College of Pharmacy, Dankook University, 119 Dandae-ro, Dongnam-gu, Cheonan-si, \\ Chungnam 31116, ${ }^{2}$ Laboratory of Host Defense Modulation, College of Pharmacy, Chung-Ang University, 221 Heukseok-dong, \\ Dongjak-gu, Seoul 06974, Republic of Korea
}

*For correspondence: Email: soypark23@dankook.ac.kr; Tel: +82-41-550-1434; Fax: +82-41-559-7899

\begin{abstract}
Purpose: To investigate the potential immune-enhancing effects of fourteen natural plant extracts on mouse macrophage RAW 264.7 cells.

Methods: Fourteen plant extracts from 7 different plants were tested on RAW 264.7 cells to determine their immunostimulant activities. Methylthiazolydiphenyltetrazolium bromide (MTT) and Griess assays were performed to evaluate cell viability and nitric oxide (NO) production, respectively. Then, immune related proteins were measured by western blot analysis, while cytokines and phagocytic activity were determined by enzyme-linked immunosorbent assay (ELISA) method.

Results: Among the 14 plant extracts, the hot water extract of Agastache rugose was selected based on the screening results on NO production. The hot water extract of A. rugose significantly increased NO production in a concentration-dependent manner without any cytotoxicity. In addition, the expression levels of proteins (iNOS and COX-2) and cytokines (TNF- $\alpha, I L-1 \beta, I L-6$ and IL-12) closely related to immune reaction were also significantly upregulated. Furthermore, phagocytic activity of RAW 264.7 cells significantly increased following treatment with A. rugosa.

Conclusion: The hot water extract of A. rugosa exhibits significant immune-stimulant activity. Therefore, A. rugosa can be used as a natural resource for immune enhancement or dietary supplement.
\end{abstract}

Keywords: Immune enhancing activity, Macrophage polarization, Natural plant extracts, Agastache rugosa, RAW 264.7

This is an Open Access article that uses a funding model which does not charge readers or their institutions for access and distributed under the terms of the Creative Commons Attribution License (http://creativecommons.org/licenses/by/4.0) and the Budapest Open Access Initiative (http://www.budapestopenaccessinitiative.org/read), which permit unrestricted use, distribution, and reproduction in any medium, provided the original work is properly credited.

Tropical Journal of Pharmaceutical Research is indexed by Science Citation Index (SciSearch), Scopus, International Pharmaceutical Abstract, Chemical Abstracts, Embase, Index Copernicus, EBSCO, African Index Medicus, JournalSeek, Journal Citation Reports/Science Edition, Directory of Open Access Journals (DOAJ), African Journal Online, Bioline International, Open-J-Gate and Pharmacy Abstracts

\section{INTRODUCTION}

The immune system is responsible for protection against infections of bacteria, viruses and fungi [1]. Macrophage is one of the representatives of innate immune cells which perform first line defense during infection initiates [2,3]. Macrophage is ubiquitously found in almost all tissues and plays an important role in immune reactions like phagocytosis [4,5]. In addition to phagocytosis, macrophage has various functions including the production of inflammatory mediators such as nitric oxide, prostaglandins 
and cytokines in response to immune stimuli leading to immune cascades [6-9]. These immune players have beneficial effects on cancers by acting as guards against cancer, but sometimes could function as a helper for tumor development through weakening of the immune response [10]. Thus, it is necessary to control its functions when necessary.

Though overactivated immune system damages host's homeostasis, weakened immune system is also significantly harmful to human health. A proper immune reaction could prevent pathologic and cancerous assault. The causes of immune suppression include stress, environmental toxin, sedentary lifestyle, inadequate sleep, alcohol and tobacco abuse, cortisone, chemotherapy, antibiotics, other drug therapy and infection [11].

Therefore, the need for medicines and supplements to boost immune system are increasing, and many researches have been done or ongoing to search for immunostimulatory natural sources which have few side effects compared to chemical drugs [12-15]. Echinacea and ginseng are well-established examples of immunostimulatory natural products [15].

The aim of this study is to investigate the immune-enhancing effects of natural product extracts with a focus on the polarization of the rodent macrophage, RAW 264.7 cells. Seven plants were selected and extracted with two different methods. The first method used $80 \%$ alcohol at room temperature and the other used hot water to extract the natural products.

A total of 14 plant extracts were employed in this research and screened using the expression level of nitric oxide (NO). The hot water extract of Agastache rugosa was selected for further studies because it gave the best activity on $\mathrm{NO}$ production. The effects of $A$. rugosa on immune related enzymes (iNOS, COX-2), cytokines (TNF- $\alpha$, IL-1 $\beta$, IL-6 and IL-12), and phagocytic activity were investigated.

\section{EXPERIMENTAL}

\section{Materials and reagents}

Griess reagent, dimethyl sulfoxide (DMSO), lipopolysaccharide (LPS, E. coli 0111:B4) were purchased from Sigma-Aldrich (St. Louis, MO, USA). Thiazoyl blue tetrazolium bromide (MTT) was acquired from biosesang (Seongnuam, Korea). The antibodies of cyclooxygenase-2 (COX-2), tubulin (TB, house keeper) (Santa Cruz Biotechnology, Dallas, TX, USA) and iNOS (BD Biosciences, San Jose, CA, USA) were used for Western blot. All antibodies of cytokines (TNFa, IL-1 $\beta$, IL-6 and IL-12) were purchased from BD Biosciences. (San Jose, CA, USA). Ethanol for the extraction of plants was obtained from Samchun (Pyeongtaek, Korea). Dulbecco's modified eagle's medium (DMEM) and fetal bovine serum (FBS) were purchased from Welgene (Gyeongsan, Korea).

\section{Plant material collection and authentication}

Seven dried plant materials (Table 1) were purchased from a commercial market (hanyakjae.net, Seoul, Korea) in 2017. Plant materials were confirmed and authenticated by Prof. S-Y Park and all voucher specimens were deposited in Pharmacognosy laboratory of College of Pharmacy, Dankook University.

\section{Extraction}

The dried and pulverized part for medical use of each plant was collected $(100 \mathrm{~g})$. It was extracted with $80 \%$ ethanol at room temperature and with hot water at a temperature that ranged between $80-90^{\circ} \mathrm{C}$. In general, the plant powder was 3-4 times extracted with enough volume of solvent soaking all powder. In case of $80 \%$ ethanol extraction the exposal time was 6 hours and then the filtrate was evaporated in vacuo to yield the extract. For the hot water extraction, the end point was when the volume of the solvent was reduced by half and the filtrate was lyophilized to obtain the extract.

Table 1: Medicinal plants and their part used traditionally in oriental medicine

\begin{tabular}{lccc}
\hline Plant name & Abbreviation & $\begin{array}{c}\text { Medicinally useful } \\
\text { part }\end{array}$ & Family \\
\hline Buddleja officinalis Maximowicz & BO & Flower & Loganiaceae \\
Morus alba Linn & MA & Fruit & Cornaceae \\
Cornus officinalis Sielbold et Zuccarini & CO & Root & Paeoniaceae \\
Paeonia lactiflora Pallas & PL & Aerial part & Labiatae \\
Agastache rugosa Fischer et Meyer & AR & & Unbelliferae \\
O.Kuntze & & Aerial part & Oleaceae \\
Angelica Kiusiana Maximowicz & AK & Fruit & FS \\
Forsythia suspensa Vahl & &
\end{tabular}




\section{Cell culture and MTT assay}

Murine macrophage cells (RAW 264.7) were cultured in DMEM supplemented with $10 \%$ FBS. The cells were incubated in a humidified $5 \%$ $\mathrm{CO}_{2}$ atmosphere at $37^{\circ} \mathrm{C}$. The cytotoxicity of plant extracts was determined by MTT assay. RAW 264.7 cells $\left(2.0 \times 10^{4}\right.$ cells) were seeded and incubated for $24 \mathrm{~h}$ before they were treated with or without plant extracts at given concentrations (20 and $100 \mu \mathrm{g} / \mathrm{mL}$ ) for 20 - $22 \mathrm{~h}$. And then $5 \mathrm{mg} / \mathrm{mL}$ of MTT solution was added to each well for $3 \mathrm{~h}$, followed with a removing the supernatants and DMSO was used for dissolving formazans. Absorbance was measured with a microplate reader (Biotek, Winooski, VT, USA) at $540 \mathrm{~nm}$. Only DMEM treated group was considered as a negative control.

\section{NO measurement}

Cells were treated with plant extracts for $20-22$ $\mathrm{h}$ and then the supernatants were reacted with same volume of Griess reagent (St. Louis, MO, USA) for $15 \mathrm{~min}$. The absorbance was checked at $540 \mathrm{~nm}$ using microplate reader (Biotek, Winooski, VT, USA). LPS treated group was used as a positive control.

\section{Western blotting analysis}

Cells were seeded in 6-well plate at $2 \times 10^{6}$ cells/well and allowed to adhere to plate for 24 hours. And then they were treated with the hot water extract of $A R$ selected from screening at given concentrations $(10,20,50$ and $100 \mu \mathrm{g} / \mathrm{mL})$ for $20-22 \mathrm{~h}$. For preparation of whole cell lysates, media was removed and cells were washed with phosphate-buffered saline (PBS) and lysed in Laemmli buffer. Proteins were separated by SDS-PAGE and transferred to nitrocellulose membranes by electroblotting. The membranes were blocked in $5 \%$ skim milk in PBS. The blots were incubated overnight at $4{ }^{\circ} \mathrm{C}$ with primary antibodies diluted in PBS followed by incubation with secondary antibodies conjugated to horseradish peroxidase in $5 \%$ skim milk for $2 \mathrm{~h}$. The target protein was detected by enhanced chemiluminescence (ChemiDoc XRS+, Biorad, Hercules, CA, USA). LPS (1 $\mu \mathrm{g} / \mathrm{mL}$ ) treated group was used as a positive control.

\section{An enzyme-linked immunosorbent assay (ELISA)}

After stimulation with the hot water extract of $A$. rugosa at given concentrations $(10,20,50$ and $100 \mu \mathrm{g} / \mathrm{mL}$ ) for $20-22 \mathrm{~h}$, the supernatant concentrations of TNF- $\alpha$, IL- $1 \beta$, IL- 6 , and IL-12 were measured by an ELISA. The 96-well plates were coated (overnight at $4{ }^{\circ} \mathrm{C}$ ) with the capture antibodies. Each well was washed three times with $0.05 \%$ Tween 20 in PBS (PBS-T), incubated with blocking solution for 1 hour at room temperature, and then washed four times with PBS-T. The samples and diluted standards were added, and the plate was incubated overnight at $4{ }^{\circ} \mathrm{C}$. After four wash cycles, the detection antibody was added. After $45 \mathrm{~min}$ of incubation at room temperature, the wells were washed. Avidin-conjugated alkaline phosphatase (Jackson ImmunoResearch, West Grove, PA, USA) was added, and the plates were incubated at room temperature for $30 \mathrm{~min}$. After that, a substrate solution was added, and the plates were kept at room temperature for $5-30 \mathrm{~min}$ before the addition of stop buffer. Absorbance was read at $405 \mathrm{~nm}$ on a microplate reader (Emax, Molecular Devices, San Jose, CA, USA). LPS $(1 \mu \mathrm{g} / \mathrm{mL})$ treated group was used as a positive control.

\section{Evaluation of phagocytic activity}

The phagocytic ability of RAW 264.7 cells was determined by the CytoSelect ${ }^{\mathrm{TM}}$ 96-well phagocytosis assay kit (Cell Biolabs Inc., San Diego, CA, USA), following the manufacturer's instructions. Cells were seeded in 96-well plate at $1 \times 10^{5}$ cells/well and allowed to attach to the plate for $24 \mathrm{~h}$. And then cells were treated with the hot water extract of $A$. rugosa (10,20, 50 and $100 \mu \mathrm{g} / \mathrm{mL}$ ), complete DMEM was used as a negative control and LPS $(1 \mu \mathrm{g} / \mathrm{mL})$ was for positive control. Subsequently, non-opsonized zymosan was addition and the amount of engulfed zymosan was measured at $405 \mathrm{~nm}$ after $2 \mathrm{~h}$ incubation at $37^{\circ} \mathrm{C}$ by microplate reader (Biotek, Winooski, VT, USA).

\section{Statistical analysis}

Data are presented as mean \pm standard deviation (SD). Statistical analysis was done by two-tailed Student t-test using Microsoft Excel 2016. Significant differences were considered at $p<0.05$.

\section{RESULTS}

\section{Effect of plant extracts on cell viability and NO production}

All plant extracts except 20 and $100 \mu \mathrm{g} / \mathrm{mL}$ of hot water extract of Angelica Kiusiana and 100 $\mu \mathrm{g} / \mathrm{mL}$ of $80 \%$ ethanol extract of $A$. rugosa did not show any toxicity as relative cell viability was over $80 \%$ compared to vehicle treated group (Figure 1). Those three groups with cytotoxicity 
were not included in NO production assay. To determine the effect of plant extracts on inducing NO in RAW 264.7, the medium supernatants were reacted with Griess reagent). As shown in Figure $2 \mathrm{~A}$, the hot water extract of Morus alba at $100 \mu \mathrm{g} / \mathrm{mL}$ showed mild but statistically significant activity to increase the release of NO. Moreover, the how water extract of $A$. rugosa dramatically induced NO production up to 4 times more than vehicle treated group (Figure $2 \mathrm{~A}$ ). However, no sign was found in groups treated with all $80 \%$ ethanol extracts (Figure $2 \mathrm{~B}$ ).
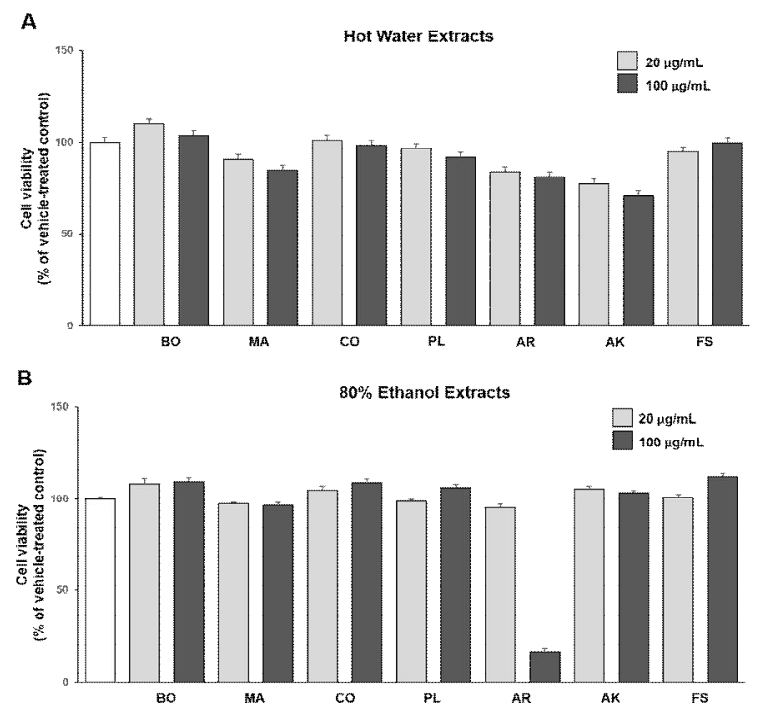

Figure 1: Effect of plant extracts on cell viability. The cell viability is seen in $(A)$ cells treated with hot water extracts and (B) cells treated with $80 \%$ ethanol extracts. The first left bar colored white is the vehicletreated group. The cell viability below $80 \%$ of vehicle treated group was considered cytotoxicity so 20 and $100 \mu \mathrm{g} / \mathrm{mL}$ of hot water extract of AK and $100 \mu \mathrm{g} / \mathrm{mL}$ of $80 \%$ ethanol extract of AR were excluded from further assays. The values are presented as mean \pm SD

\section{Effect of hot water extract of AR on NO production and protein expression}

To confirm the effect of hot water extract of AR on NO production, various concentrations (10, 20, 50 and $100 \mu \mathrm{g} / \mathrm{mL}$ ) of $A$. rugose were applied to RAW 264.7 cells. The hot water extract of AR significantly increased NO release in a concentration-dependent manner (Figure 3). The treatment with $10 \mu \mathrm{g} / \mathrm{mL}$ (lowest concentration) also increased the production of NO up to $270 \%$ compared to vehicle treated group.

COX-2 and iNOS, immune related proteins which can be activated with macrophage polarization, were determined by Western blot.

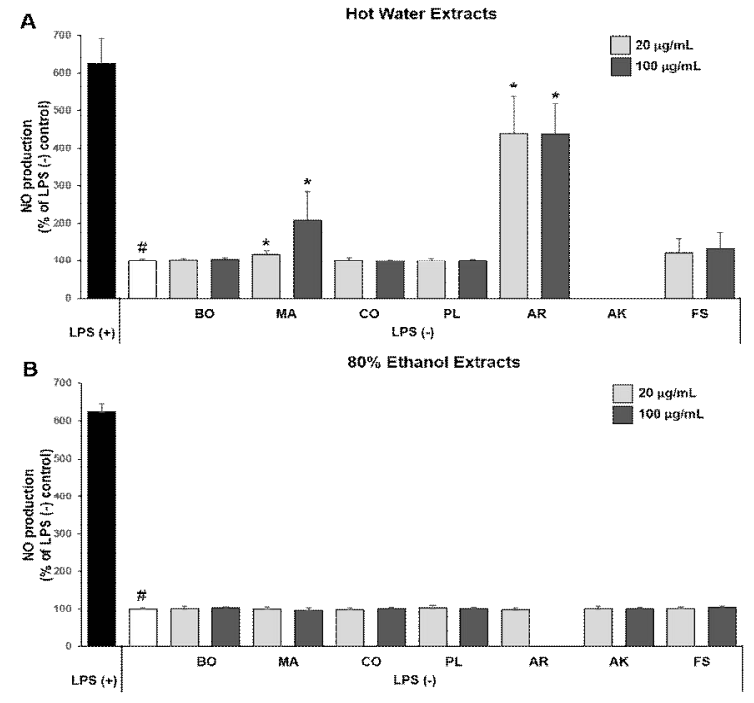

Figure 2: Effect of plant extracts on NO production. The NO expression was measured from media supernatants of $(A)$ cells treated with hot water extracts and (B) cells treated with $80 \%$ ethanol extracts. The first left bar colored black is LPS treated group (LPS (+)) and the second left bar colored white is vehicle treated group (LPS $(-))$. The hot water extract of MA and AR enhanced NO production at both concentrations treated. The increase of NO production was analyzed by two-tailed Student t-test $(\# p<0.05$ : LPS (+) vs. LPS (-) and ${ }^{*} p<0.05$ : LPS (-) vs each plant extract treated group). The values are presented as mean $\pm S D$

The hot water extract of $A$. rugosa increased iNOS level in a concentration dependent manner though only $100 \mu \mathrm{g} / \mathrm{mL}$ treated group reached statistical significance (Figure $4 \mathrm{~B}$ ). On the other hand, this extract elevated COX-2 expression more clearly, that is to say that statistical significance was observed in 10,50 and 100 $\mu \mathrm{g} / \mathrm{mL}$ of treatments compared to vehicle treated group (Figure $4 \mathrm{~A}$ ).

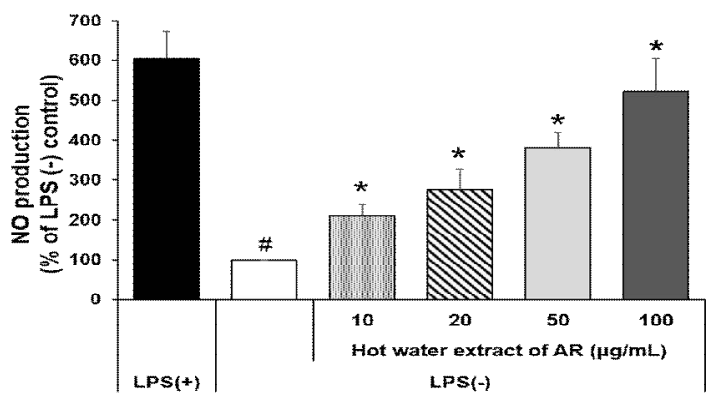

Figure 3: Effect of hot water extract of AR on NO production with a wider range of concentrations (10, 20,50 and $100 \mu \mathrm{g} / \mathrm{mL}$ ). The first left bar colored black is LPS treated group (LPS (+)) and the second left bar colored white is vehicle treated group (LPS (-)). The increase of NO production was analyzed by two-tailed Student t-test (\#p < 0.05: LPS (+) vs. LPS (-) and ${ }^{*} p<$ 0.05 : LPS (-) vs each concentration treated group). The values are presented as mean \pm SD 

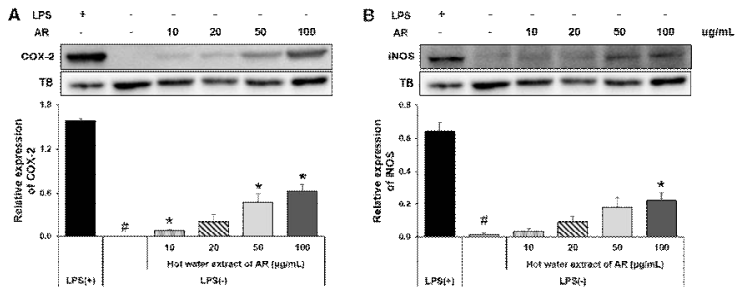

Figure 4: Effect of hot water extract of $A R$ on relative expression of COX-2 (A) and iNOS (B) with given concentrations $(10,20,50$ and $100 \mu \mathrm{g} / \mathrm{mL})$. The first left bar colored black is LPS treated group (LPS (+)) and the second left bar colored white is vehicle treated group (LPS (-)). The amount of the two enzymes was quantified according to the spot density of each group and followed by normalized by the house keeper protein, TB. The increase of relative expression of enzymes was analyzed by two-tailed Student t-test (\#p $<0.05$ : LPS (+) vs. LPS (-) and ${ }^{*} p<0.05$ : LPS (-) vs each concentration treated group). The values are presented as mean \pm SD

\section{Effect of hot water extract of AR on cytokine expression}

Cytokines such as TNF- $\alpha$, IL-1 $\beta$, IL- 6 and IL-12, which are important in immune responses were measured by ELISA method. The concentration of cytokines was calculated by standard curve of each one. The hot water extract of $A$. rugosa upregulated the production of all cytokines known to be secreted from macrophage concentration-dependently compared to vehicle treated group (Figure 5). In case of TNF- $\alpha$, the treatment of $A$. rugosa hot water extract increased TNF- $\alpha$ up to the level of LPS treated group.

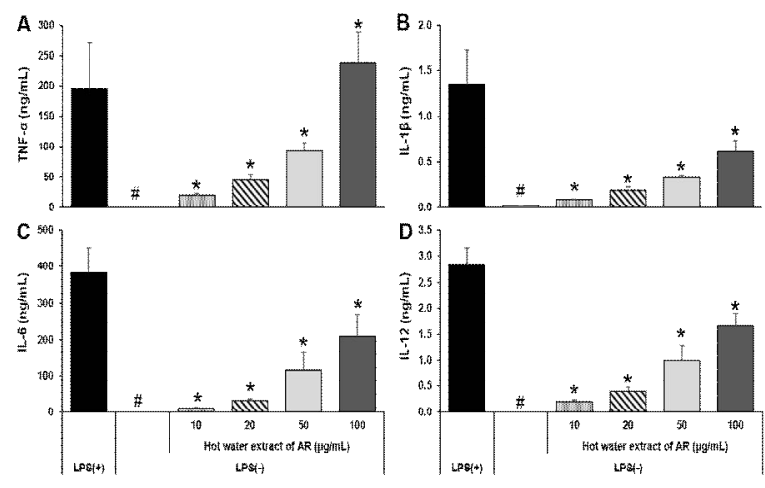

Figure 5: Effect of hot water extract of $A R$ on production of proinflammatory cytokines such as TNF$\alpha(A), I L-1 \beta(B), I L-6(C)$ and IL-12 (D) with given concentrations $(10,20,50$ and $100 \mu \mathrm{g} / \mathrm{mL})$. The first left bar colored black is LPS treated group (LPS (+)) and the second left bar colored white is vehicle treated group (LPS $(-)$ ). The concentration of the four cytokines was quantified by ELISA using the standard curve of each one. The increase of relative expression of enzymes was analyzed by two-tailed Student t-test $\left(\# p<0.05\right.$ : LPS (+) vs. LPS (-) and ${ }^{*} p<0.05$ : LPS (-) vs each concentration treated group). The values are presented as mean $\pm \mathrm{SD}$

\section{Effect of hot water extract of AR on phagocytic activity}

Phagocytosis is one of crucial functions that the macrophage conducts for defending the host from xenobiotics. Phagocytic activity was evaluated with a commercial kit through checking the amount of engulfed zymosans isolated from yeasts. The hot water extract of $A$. rugosa significantly enhanced phagocytic ability compared to vehicle treated group in all concentrations employed (Figure 6). Even 10 $\mu \mathrm{g} / \mathrm{mL}$ of the hot water extract of AR increased level of phagocytic activity close to the LPS treated group.

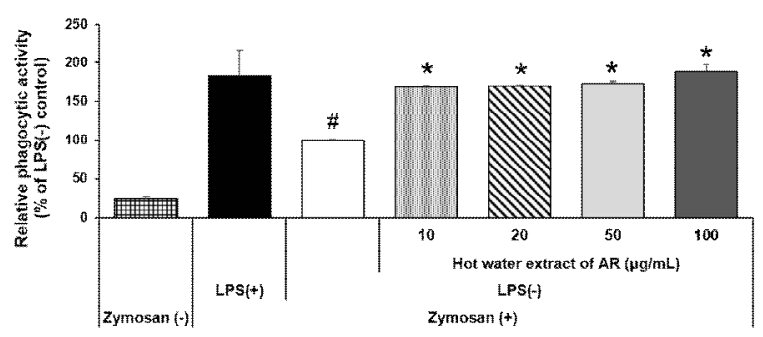

Figure 6: Effect of hot water extract of $A R$ on phagocytic activity with given concentrations (10, 20, 50 and $100 \mu \mathrm{g} / \mathrm{mL}$ ). The first left bar colored white with cross stripes is zymosan free group and the second left bar colored black and the third bar colored white are LPS treated (LPS (+)) and vehicle treated group (LPS (-)) respectively. The relative phagocytic activity was normalized by LPS (-) group. The increase of relative expression of enzymes was analyzed by twotailed Student t-test $(\# p<0.05$ : LPS (+) vs. LPS (-) and ${ }^{*} p<0.05$ : LPS (-) vs each concentration treated group). The values are presented as mean \pm SD

\section{DISCUSSION}

In this study a total of 14 plant extracts from 7 plants were obtained using two different methods, $80 \%$ ethanol and hot water extraction. After screening for cytotoxicity and NO production in RAW 264.7 cells the hot water extract of $A$. rugosa was selected as the best candidate and used for further study. The hot water extract of $A$. rugosa successfully increased Immune associated proteins and cytokines and phagocytic activity.

Macrophage has two faces depending on the microenvironment in general. When macrophage is exposed to T1 cytokines, IFN- $\gamma$, TNF $\alpha$ and GM-CSF, or LPS, it can be polarized to become M1 type [16]. In contrast, M2 polarization of macrophage is initiated with cytokines IL-4 and 13 produced by Th2 cells, mast cells, and 
basophil [17]. These two types M1 and M2 show totally different actions in the immune system. M1 macrophages produce proinflammatory cytokines such as TNF- $\alpha, \mathrm{IL}-1 \beta, \mathrm{IL}-6, \mathrm{IL}-12$ and IL-15and chemokine like CXCL10 [16]. In addition, it could express reactive oxygen intermediates (ROI) and $\mathrm{NO}$ and $\mathrm{MHC}$ class II found on the surface [18]. Consequently, M1 macrophage leads to immune activation that attacks xenobiotics or cancer.

On the other hand, M2 macrophage characterized by high expression of macrophage mannose receptor downregulates iNOS expression with upregulation of argnase-1 expression [19]. Furthermore, cytokines produced by $\mathrm{M} 2$ are anti-inflammatory cytokines such as TGF- $\beta$, IL-10 and IL-1 receptor antagonist [20]. Of course, M2 macrophage play a beneficial role in autoimmune disease but could be used as a survival strategy for tumor or some bacterial pathogens $[21,22]$. Thus, unless immune system is abnormally overactivated it is important to keep macrophages in the M1 phase as they are able to augment immune reaction from bacterial and cancerous invasions.

Also, in cases of some pathogen like Salmonella and pancreatic cancer they redirect the phenotype of macrophages from M1 phase to M2 phase for their survival in the hosts. [21]. Moreover, aging, medication like chemotherapy and virus infection such as AIDS cause the immune system to be compromised leading to exacerbation of the host's health [21]. Therefore, it is beneficial and necessary that macrophage should stay polarized in the M1 phenotype for the defense of infections or cancerous assault.

The hot water extract of $A$. rugosa has immunostimulant activity through macrophage polarization. The plant $A$. rugosa (Korean mint) is used as natural medicine traditionally in Asia in particular Korea, to treat colds, anorexia, cholera, vomiting, and miasma [23]. Various essential oils like eugenol and its derivatives, flavonoids such as tilianin and acacetin, and lignans like rosmarinic acid were isolated from $A$. rugosa [24]. Many researches about pharmacological activities of $A$. rugosa have been established including antimicrobial, antifungal, antioxidative $[25,26]$. The methanol extract of $A$. rugosa and its main component, tillianin showed inhibitory effect on cytokine induced cell adhesion molecule-1 leading to atherosclerosis, a chronic inflammatory disease [27]. Interestingly, Oh et al. reported that $90 \%$ methanol extract of $A R$ decreased inflammatory level in rat osteosarcoma cell line stimulated with cytokine mixture [28]. Additionally, rosmarinic acid known as one of the representative components isolated from $A$. rugosa was reported to show antiinflammatory effect [29]. However, the hot water extract of $A$. rugosa showed immunostimulant effect.

This result suggests that different extraction methods of the same medicinal plant could give completely opposite biological activities due to the different composition of chemical constituents extracted. Flavonoids and lignans such as tilianin and rosmarinic acid as well as some amounts of volatile oil could be obtained by alcohol extraction and they showed anti-inflammatory and antibiotic effect the constituents of hot water extraction might be different.

Most polysaccharides and hydrophilic compounds which have one or two even more sugars in their structures can be extracted in hot water. These compounds might boost the immune system through polarization of immune cells or they might be able to play a role like LPS without any toxic response. $\beta$-glucan isolated from mushrooms has been reported to be one of the famous natural immunostimulant polysaccharides and ginsenosides, triterpene glycosides with several sugars also are discovered to have immune enhancing effect $[15,30]$. Thus, natural resources already reported to have even anti-inflammatory effect could have immune-enhancing activity if the extraction method is changed.

\section{CONCLUSION}

The findings of this study show that out of a total of 14 plant extracts tested for immunostimulant activities, only the hot water extract of $A$. rugosa has been confirmed to boost immune reaction via macrophage polarization, based on the expression levels of immune related molecule (NO), proteins (iNOS and COX), cytokines (TNF$\alpha, I L-1 \beta, I L-6$ and IL-12) and phagocytic activity. Therefore, the hot water extract of $A R$ is a potential immune-enhancing natural agent and/or dietary supplement. However, these effects require confirmation via in vivo studies.

\section{DECLARATIONS}

\section{Acknowledgement}

This work was supported by Korea Institute of Planning and Evaluation for Technology in Food, Agriculture, Forestry and Fisheries (IPET) through High Value-Added Food Technology Development Program, funded by Ministry of 
Agriculture, Food and Rural Affairs (MAFRA, no. 316062-3).

\section{Conflict of Interest}

No conflict of interest associated with this work.

\section{Contribution of Authors}

The authors declare that this work was done by the authors named in this article and all liabilities pertaining to claims relating to the content of this article will be borne by them.

\section{REFERENCES}

1. Parham P. The immune system. 3rd ed. Milton Park: Garland Science; 2009; pp 1-2.

2. Schultze JL, Schmidt SV. Molecular features of macrophage activation. Semin Immunol 2015; 27(6): 416-423

3. McCabe A, MacNamara KC. Macrophages: Key regulators of steady-state and demand-adapted hematopoiesis. Exp Hematol 2016; 44: 213-222

4. Kudrin A, Ray D. Cunning factor: macrophage migration inhibitory factor as a redox-regulated target. Immunol Cell Biol 2008; 86: 232-238

5. Krneta $T$, Gillgrass A, Ashkar $A A$. The influence of macrophages and the tumor microenvironment on natural killer cells. Curr Mol Med 2013; 13: 68-79

6. Kalinski P. Regulation of immune responses by prostaglandin E2. J Immunol 2012; 188: 21-28

7. Balkwill F. Tumour necrosis factor and cancer. Nat Rev Cancer 2009; 9: 361-371

8. Murakami A, Ohigashi H. Targeting NOX, INOS and COX-2 in inflammatory cells: chemoprevention using food phytochemicals. Int J Cancer 2007; 121: 23572363

9. Liu Y, Jiao F, Qiu Y, Li W, Qu Y, Tian C, Li Y, Bai R, Lao $F$, Zhao $Y$, et al. Immunostimulatory properties and enhanced TNF- alpha mediated cellular immunity for tumor therapy by $\mathrm{C}_{60}(\mathrm{OH})_{20}$ nanoparticles. Nanotechnol 2009; 20: 415102

10. Mills CD, Kincaid K, Alt JM, Heilman MJ, Hill AM. M-1/M2 macrophages and the Th1/Th2 paradigm. J Immunol 2000; 164: 6166-6173

11. Jang M, Lim TG, Ahn S, Hong HD, Rhee YK, Kim KT, Lee $E$, Lee JH, Lee $Y J$, Jung $C S$ et al. ImmuneEnhancing Effects of a High Molecular Weight Fraction of Cynanchum wilfordii Hemsley in Macrophages and Immunosuppressed Mice. Nutrients 2016; 8 : doi:10.3390/nu8100600

12. Zhang A, Yang $X$, Li Q, Yang $Y$, Zhao G, Wang B, Wu D. Immunostimulatory activity of water-extractable polysaccharides from Cistanche deserticola as a plant adjuvant in vitro and in vivo. PLoS One 2018; 13: e0191356
13. Kwon DH, Cheon JM, Choi EO, Jeong JW, Lee KW, Kim $K Y$, Kim SG, Kim S, Hong SH, Park C, et al. The Immunomodulatory Activity of Mori folium, the Leaf of Morus alba L., in RAW 264.7 Macrophages In Vitro. J Cancer Prev 2016; 21: 144-151

14. Kim JY, Byeon SE, Lee YG, Lee JY, Park J, Hong EK, Cho JY. Immunostimulatory activities of polysaccharides from liquid culture of pine-mushroom Tricholoma matsutake. J Microbiol Biotechnol 2008; 18: 95-103

15. Block KI, Mead MN. Immune system effects of echinacea, ginseng, and astragalus: a review. Integr Cancer Ther 2003; 2: 247-267

16. Solinas G, Germano G, Mantovani A, Allavena P. Tumorassociated macrophages (TAM) as major players of the cancer-related inflammation. J Leukoc Biol 2009; 86: 1065-1073

17. Varin A, Gordon $S$. Alternative activation of macrophages: immune function and cellular biology. Immunobiol 2009; 214: 630-641

18. Movahedi K, Laoui D, Gysemans C, Baeten M, Stange G, Van den Bossche J, Mack M, Pipeleers D, In't Veld $P$, De Baetselier $P$, et al. Different tumor microenvironments contain functionally distinct subsets of macrophages derived from Ly6C(high) monocytes. Cancer Res 2010; 70: 5728-5739

19. Gordon S, Martinez FO. Alternative activation of macrophages: mechanism and functions. Immunity 2010; 32(5): 593-604

20. Pollard JW. Trophic macrophages in development and disease. Nat Rev Immunol 2009; 9: 259-270

21. Fu A, Wang Y, Wu Y, Chen H, Zheng S, Li Y, Xu X, Li W. Echinacea purpurea Extract Polarizes M1 Macrophages in Murine Bone Marrow-Derived Macrophages Through the Activation of JNK. J Cell Biochem 2017; 118: 26642671

22. Martinez FO, Helming L, Gordon S. Alternative activation of macrophages: an immunologic functional perspective. Annu Rev Immunol 2009; 27: 451-483

23. Kim YB, Kim JK, Uddin MR, Xu H, Park WT, Tuan PA, Li $X$, Chung $E$, Lee JH, Park SU. Metabolomics analysis and biosynthesis of rosmarinic acid in Agastache rugosa Kuntze treated with methyl jasmonate. PLoS One 2013; 8: e64199

24. Li HQ, Liu QZ, Liu ZL, Du SS, Deng ZW. Chemical composition and nematicidal activity of essential oil of Agastache rugosa against Meloidogyne incognita. Molecules 2013; 18: 4170-4180

25. Swarup V, Ghosh J, Ghosh S, Saxena A, Basu A. Antiviral and anti-inflammatory effects of rosmarinic acid in an experimental murine model of Japanese encephalitis. Antimicrob Agents Chemother 2007; 51: 3367-3370

26. Gao LP, Wei $H L$, Zhao HS, Xiao SY, Zheng $R L$. Antiapoptotic and antioxidant effects of rosmarinic acid in astrocytes. Pharmazie 2005; 60: 62-65

27. Hong JJ, Choi JH, Oh SR, Lee HK, Park JH, Lee KY, Kim JJ, Jeong TS, Oh GT. Inhibition of cytokine-induced vascular cell adhesion molecule-1 expression; possible

Trop J Pharm Res, January 2019; 18(1): 91 
mechanism for anti-atherogenic effect of Agastache rugosa. FEBS Lett 2001; 495: 142-147

28. Oh HM, Kang YJ, Kim SH, Lee YS, Park MK, Heo JM, Sun J, Kim HJ, Kang ES, Seo HG et al. Agastache rugosa leaf extract inhibits the iNOS expression in ROS 17/2.8 cells activated with TNF-alpha and IL-1beta. Arch Pharm Res 2005; 28: 305-310

29. Rocha J, Eduardo-Figueira M, Barateiro A, Fernandes A, Brites $D$, Bronze $R$, Duarte $C M$, Serra AT, Pinto $R$,
Freitas $M$, et al. Anti-inflammatory effect of rosmarinic acid and an extract of Rosmarinus officinalis in rat models of local and systemic inflammation. Basic Clin Pharmacol Toxicol 2015; 116: 398-413.

30. Chan GC; Chan WK; Sze DM. The effects of beta-glucan on human immune and cancer cells. J Hematol Oncol 2009; 2: 25. 